\title{
Research on the Near Net Shape Hollow Forging Technology for CAP 1400 Main Pipe
}

\author{
Wang Baozhong', Liu Ying ${ }^{2}$, Guo Yi $^{2}$, Nie Yihong ${ }^{2}$ \\ ${ }^{1}$ China First Heavy Industries, Qiqihaer, China \\ ${ }^{2}$ Tianjin Heavy Industries Research \& Development Co, Ltd, Tianjin, China
}

Email address:

wang.bz@cfhi.com (WangBaozhong),zhangliu92@126.com(Liu Ying),13514643319@139.com(Guo Yi), nieyihong@126.com(Nie Yihong)

\section{To cite this article:}

Wang Baozhong, Liu Ying, Guo Yi, Nie Yihong. Research on the Near Net Shape Hollow Forging Technology for CAP 1400 Main Pipe. International Journal of Mechanical Engineering and Applications. Vol. 6, No. 2, 2018, pp. 18-22. doi: 10.11648/j.ijmea.20180602.11

Received: March 19, 2018; Accepted: April 9, 2018; Published: May 8, 2018

\begin{abstract}
It has been widely focused because of its complex integral-structure and strict technical requirement since AP1000 main pipe appeared, which is made by $316 \mathrm{LN}$ stainless steel. After ten years of effort and exploring, excellent forging suppliers from all over the world agree that 316LN heavy forgings including AP1000 only can be formed by relatively simple solid forging technology though the grain size cannot meet the initial design requirement of ASTM level-4. The design concept of CAP1400 main pipe is the same as AP1000, in which the straight part, curving part and two supper-long asymmetrical nozzles should be an integrated structure manufactured by $316 \mathrm{LN}$ steel. But due to larger dimension and higher requirement for technology, the manufacturing of CAP1400 is more difficult. In order to realize the near net shape manufacturing of CAP1400 main pipe, we invent a green manufacturing technology with highly asymmetrical nozzle for stainless steel main pipe hollow forgings, We have successfully manufactured a stainless hollow forgings using a 78t ESR ingot with nozzle height of $400 \mathrm{~mm}$, wall thickness of $160 \mathrm{~mm}$, total length of 9000mm, and ASTM level 4-6 of grain size for each part.
\end{abstract}

Keywords: Hollow Forgings, Near Net Shape Manufacturing, Grain Size

\section{Introduction}

Stainless steel has been widely and deeply concerned since the advent of it which has been the beloved of the material industry. Whether it is the richness and development of the material types or the analysis and understanding of the material properties, the microscopic mechanism research and the macroscopic practice exploration have been continued [1-3]. There are many 'good experiences' for stainless steel forgings such as the narrow deformation temperature range, the higher deformation resistance, the objective existence of harmful phases such as ferrite and the impossibility of grain size improvement by the phase change heat treatment and so on $[4,5]$, which are intertwined closely, so that the production of large stainless steel forgings are faced with a severe test, which large and unevenness of grain is the outstanding global problems so far.

\section{Regret of Hot Leg a Manufacturing for AP1000 Main Pipe}

The manufacture of large stainless steel main pipe is a difficult technical challenge, which is caused by its complex shape and the contradictory relationship between the technical requirements and the material characteristics of the procurement specification. In addition to satisfying requirements of the product size and shape, the grain size at different stages must satisfy the selected multiple ultrasonic testing needs of manufacturing process and the final performance test requirements [6]. Since the advent of AP1000 main pipe with 316LN nitrogen-controlled stainless steel forgings, it has attracted much attention by complex overall structure and harsh technical requirements, and inspires the enthusiasm and the determination of many professional to win the crown pearl [7-9]. The various research reports continue to emerge as a representative of the literature [10]. However, the global leader of forging suppliers have said that large 316LN stainless steel forgings like the AP1000 main pipe can only be 
formed by relatively simple solid forging technology after nearly a decade of efforts and explorations, but the grain size cannot achieve the initial design requirement, which is ASTM level-4 or more. In desperation, the grain size of AP1000 main pipe forging has to be reduced from ASTM level-4 to ASTM level-2.

\section{Research on the Near Net Shape Hollow Forging Technology for CAP 1400 Main Pipe}

The design concept of CAP1400 is the same as AP1000. The part weighs about $17 \mathrm{t}$. However, due to the larger size and the stricter technical requirement, the manufacturing difficulty is further rising.

\subsection{Main Dimensions and Technical Requirements}

(1) Main design Dimensions

Figure 1 is the main design dimensions of CAP1400 main pipe hot leg A. The height distance of the end face of two pipe nozzle each other into a 45 degree angle and the pipe axis is $934 \mathrm{~mm}$. The largest outer diameter of the larger pipe nozzle is $757 \mathrm{~mm}$, and the largest outer diameter of the lesser pipe nozzle is $652.5 \mathrm{~mm}$. The spread length of central axis in CAP1400 main pipe is about $6690 \mathrm{~mm}$.

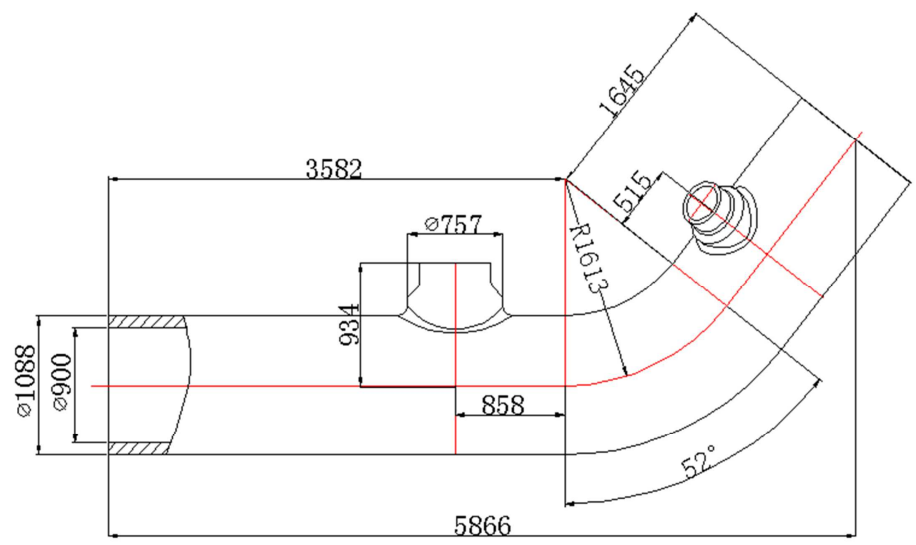

Figure 1. Main design dimensions of CAP1400 main pipe hot leg A.

(2) Major technical requirements

The chemical composition of the main pipe hot leg A should be analyzed according to ASTM A751. The main mechanical properties of the main pipe hot leg A which is in solution heat treated condition shall meet the requirements of ASTM level-2 or finer (ASTM level-3 or finer is better).

\subsection{Analysis of Difficulties in Forging Technology}

(1) Narrow forging temperature range

It is well known that the forging temperature range of austenitic stainless steels is narrow, which is determined by its lower melting point and higher recovery recrystallization temperature.

(2) Large deformation resistance

316 austenitic stainless steel has much higher temperature resistance than low alloy steel, and deformation resistance of the main pipe $316 \mathrm{LN}$ stainless steel with $\mathrm{N}$ content in $0.1 \sim 0.16 \%$ is greater than 316 stainless steel. The height distance of the end face of main pipe nozzle and the pipe axis is $934 \mathrm{~mm}$. If the main pipe billet is forged into a solid forging with flanges, the diameter of the flange is close to $2000 \mathrm{~mm}$. The weight of the electric slag remelted (ESR) ingot is about 120 tons. It is difficult to achieve the large deformation in high temperature by using the $100 \mathrm{MN}$ press. Inadequate deformation will not only make the grain coarsening of the inside of the forging internal, especially the root of pipe nozzle, but also cause UT detection unqualified of the center of forgings in a large diameter range. A Chinese forging supplier has encountered the scrapped situation because of UT detection unqualified of CAP1400 main pipe solid forging forged by using of ESR ingot.

(3) Serious forging cracking and difficult crack cleaning

Various studies have shown that primary cause of stainless steel forging cracking is the presence and precipitation of harmful phases in it such as ferrite. Due to gas cutting and other flame cleaning methods will cause the local carbon content increasing in stainless steel, which makes the more serious crack the more cleaning, so the forging must be cooled to room temperature and the crack must be cleaned thoroughly using the machine when the cracking is very serious.

(4) Large and uneven grain size

Two higher nozzles determine the deformation of the department is difficult to keep consistent with the body, and the grain size of stainless steel depends on the deformation degree, so it is very difficult to ensure that the main pipe nozzles and the pipe body meet the same grain size requirements. At the present, there is mixed crystal phenomenon in most main pipes which have been produced.

\subsection{Research on the Near Net Shape Forming of Pipe Hollow Forgings}

To solve the technological difficulty, Thermal Insulation Forging, Temperature Gradient Forging and Partial Extruding which represent the green manufacturing technology for 
stainless steel main pipe hollow forgings with highly asymmetrical nozzles were invented by CFHI . A stainless steel hollow forging using a 78t ESR ingot with nozzle height of $400 \mathrm{~mm}$, wall thickness of $160 \mathrm{~mm}$, total length of $9000 \mathrm{~mm}$, has been manufactured successfully (Figure 2).

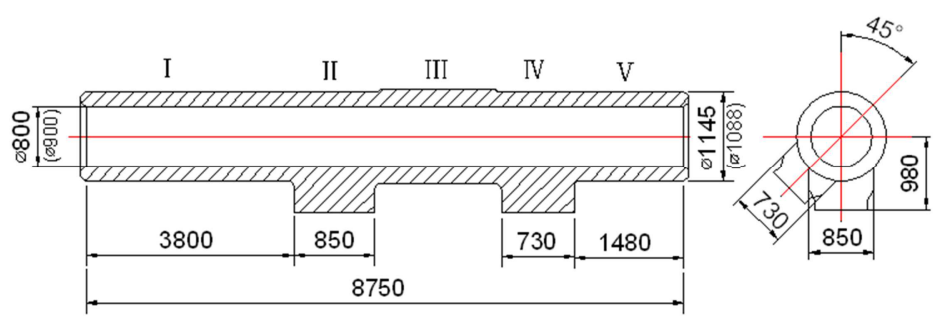

Figure 2. The full scale figure of main pipe hollow forging for CAP1400.

(1) The near net shape forging sequence is constituted of the following operations: Upsetting - Punching - Pre-drawingSection drawing (part I, III \& V)- Nozzles preforming (part II\&IV)-Nozzles extruding (part II\&IV)-Finishing.

(2)Process program of the near net shape forging.

1) Step heating approach was used in the step of high temperature heating. The crack was restrained by enough holding time at the temperature which is in favor of ferrites dissolution meanwhile the grain size grown not obviously. The experimental results indicate that with the increasing heating temperature and holding time the precipitation of ferrites were reduced and the needle-like ferrites broke to rod shaped ferrites, showed on Figure 3. All these changes can restrain forging crack, but the grain size grows obviously at higher temperature. Figure 4 is shown an illustration of the grain size growing of 316 stainless steel with different compositions upper $1000^{\circ} \mathrm{C}$. So the temperature of ferrites dissolution in product should take the above factors into consideration.
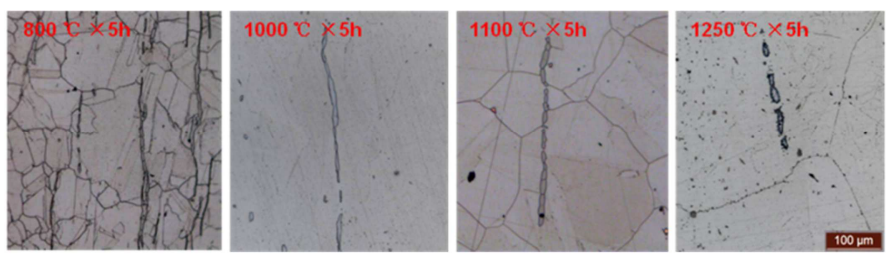

a) the same holding time at different temperature
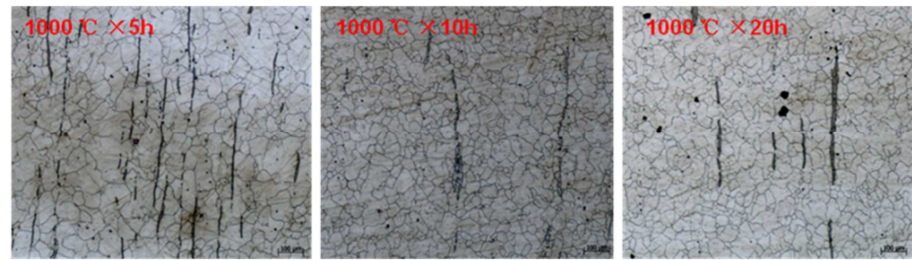

b) different holding time at the same temperature

Figure 3. The evolution for the ferrite Phase in stainless steel forging for different heating temperature and holding time.

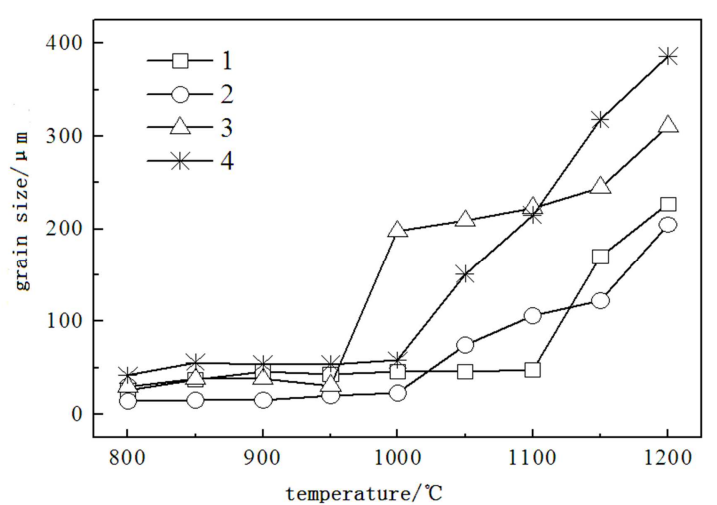

Figure 4. The grain size growing curve of 316 stainless steel with different compositions $1-0.12 \% \mathrm{~N} ; \quad 2-0.15 \% \mathrm{~N}+0.05 \% \mathrm{Nb} ; \quad 3-0.05 \% \mathrm{Nb}+0.004 \% \mathrm{~N}$; $4-0.004 \% N$.
2) Process combined large deformation at high temperature and small deformation at sub-high temperature, which is lower than the second recrystallization temperature.

Large deformation at high temperature is conducive to grain refining. Small deformation following at sub-high temperature is conducive to keep the fine grain obtained not growing.

3) Thermal Insulation Forging.

The results of material science research and commercial process show that for fine and homogeneous grain the final forging temperature should not be too low as most suitable for $900^{\circ} \mathrm{C}[2,3]$. So in order to realize the thermal insulation forging, special asbestos were used to envelop the forgings.

4) Temperature gradient forging for nozzles preforming.

Plum blossom-protrusion forging was pressed to realize the near net shape forming for nozzles in the performing [11]. The above method was effective, but the inner bore was out of 
shape and like ellipse. To prevent the deformation, Temperature Gradient Forging which cooling inner bore was used in nozzles preforming. Numerical simulation result (Figure 5) shows the Temperature Gradient Forging alleviate the elliptic deformation effectively in the preforming when plum blossom-protrusion forging was pressed.

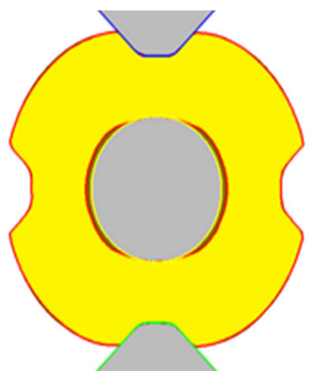

a) inner bore not cooled

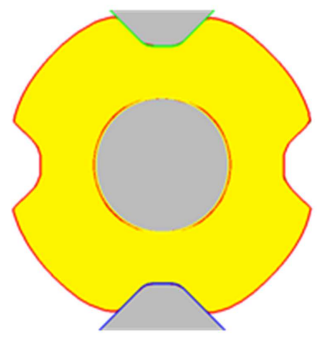

b) cooled inner bore

Figure 5. Contrast of the inner bore cooled and not cooled when plum blossom-protrusion forging was pressed.

5) Partial Extruding for nozzles final-forming.

Partial Extruding for nozzles is the key step of the green manufacturing technology for stainless steel main pipe hollow forgings with highly asymmetrical nozzles. It could not only increase the height of the nozzles to reduce the weight of the ingot consequently, but also raise the forging ratio of nozzle root to ensure that the grain size stay the same level for each part. Numerical simulation result of Partial Extruding for nozzles (Figure 6) shows that Partial Extruding can realize the near net shape forming for nozzles very well.

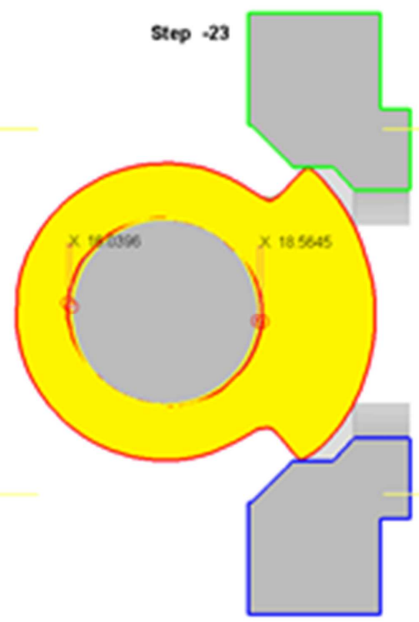

a) nozzles before extruding

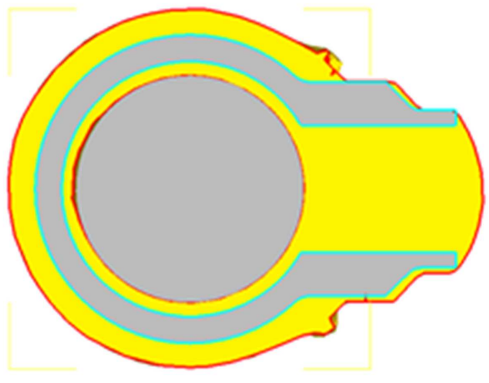

b) nozzles after extruding

Figure 6. Numerical simulation result of Partial Extruding for nozzles.

\subsection{Preproduction of Hollow Forging's Near Net Shape Forming}

Based on numerical simulation and optimization, the advanced near net shape manufacturing technology above-mentioned was used in the preproduction of CAP1400 main pipe hot leg A hollow forgings. The sequence of preproduction was showed in Figure 7.

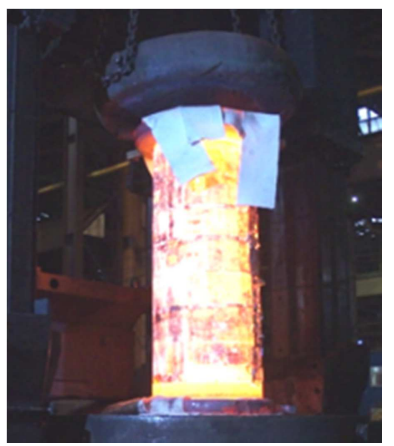

a) Upsetting

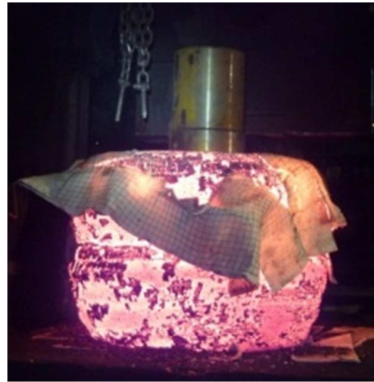

b) Punching

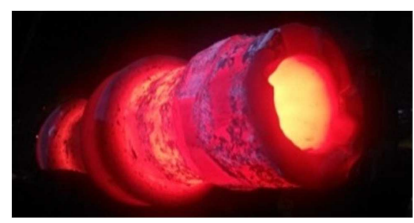

c) Drawing

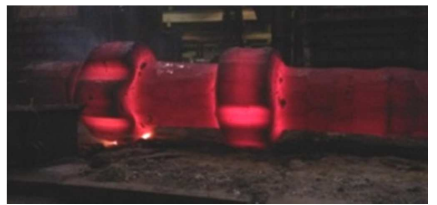

d) Pressed plum blossom-protrusion forging in nozzles preforming 


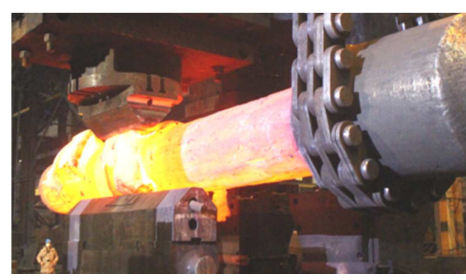

e) Partial Extruding for nozzles

Figure 7. Preproduction of CAP1400 main pipe hot leg A hollow forgings.

\subsection{Results of Hollow Forging' S near Net Shape Forming}

Figure 8. shows that ASTM level for each part in final-formed forgings was in the $4 \sim 6$ range and minimum detectable defect size was in the $3 \mathrm{~mm}$ range used probe frequency with $1 \mathrm{MHz}$.

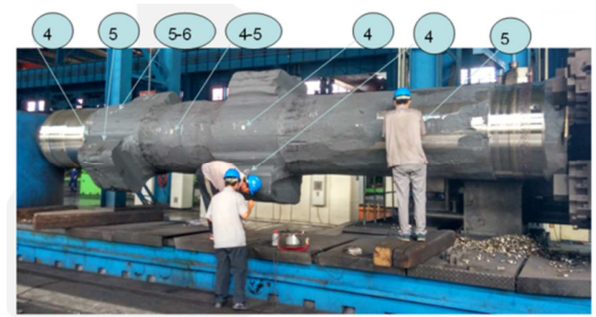

Figure 8. ASTM level and ultrasonic test for CAP1400 main pipe hot section hollow forgings.

\section{Conclusion}

The green manufacturing technology for stainless steel main pipe hollow forgings with highly asymmetrical nozzle invented by CFHI, including Thermal Insulation Forging, Temperature Gradient Forging and Partial Extruding can realize the near net shape manufacturing of CAP1400 main pipe hot leg A hollow forgings. Flow line around the nozzle was continuous and the grains of the forging for each part were fine and homogeneous with ASTM level $4 \sim 6$, and raw material consumption was reduced by $35 \%$.

\section{Acknowledgements}

This research was supported by the National Major Poject under grant No. 2015ZX060002004.

\section{References}

[1] Siqueira R P, Sandim H R Z, Oliveira T R. Texture evolution in $\mathrm{Nb}$-containing ferritic stainless steels during secondary recrystallization. Materials Science and Engineering A 2008, Vol. 497, 216-223.

[2] Choi J S, Yoon Y. The temperature dependence of abnormal grain growth and grain boundary faceting in $316 \mathrm{~L}$ stainless steel. ISIJ International 2001, Vol. 41, No. 5, 478-483.

[3] Shirdel M, Mirzadeh H, Parsa M H. Abnormal grain growth in AISI 304L stainless steel. Materials Characterization 2014, Vol. 97, 11-17.

[4] Guyot E, Lebarrois E, Martin B. Advantages of the new AREVA equipment for the forging of nuclear reactor strainless steel main coolant lines, 19th international forgemasters Meeting 2014, 164-167.

[5] Ceccon T. The most common failures of hot forging process of stainless steel and Ni-alloys. 19th international forgemasters Meeting 2014, 426-430.

[6] Wang Baozhong, et al. Green manufacturing technology for super heavy nuclear power forging [M]. Beijing: China Machine Press, 2017.

[7] Pan pinli, Zhong Yuexian, Ma Qingxian. Development of manufacture technology for main pipe of large-sized nuclear power. China Metalforming equipment and manufacturing technology 2011, No.1, 13-17.

[8] Chen Hongyu, Song Shukang, Du Junyi. Manufacturing technology progress for AP1000 forging main pipeline. Heavy casting and forging 2013, No.2, 13.

[9] Lu Huaxing. Research and development of AP1000 reactor coolant pipe in china. Shanghai metals 2010, Vol.32, No.4, 29-32.

[10] Wang Baozhong, Guo Yi, Zhang Wenhui, Liu Chenghe. Development of mono-block forged main coolant piping for AP1000. 18th international forgemasters Meeting, 2011, 258-262.

[11] Wang Baozhong, et al. Green manufacturing technology and practice of super large nuclear power forgings [M]. Beijing: China Machine Press, 2017. 